\title{
Comparison of the reliability and efficacy of LigaSure hemorrhoidectomy and a conventional Milligan-Morgan hemorrhoidectomy in the surgical treatment of grade 3 and 4 hemorrhoids
}

Mustafa Celalettin Haksal', Ali Çiftci², Çağıı Tiryaki², Murat Burç Yazıııoğlu², Mehmet Özyıldız², Selim Yiğit Yıldız²

\begin{tabular}{|c|c|}
\hline \multirow[t]{5}{*}{ ABSTRACT } & $\begin{array}{l}\text { Objective: The aim of this study was to compare the clinical results of LigaSure-assisted hemorrhoidectomy and Milli- } \\
\text { gan-Morgan hemorrhoidectomy as a conventional method in our clinic. }\end{array}$ \\
\hline & $\begin{array}{l}\text { Materials and Methods: Patients who underwent LigaSure-assisted hemorrhoidectomy or conventional hemorrhoid- } \\
\text { ectomy for grade } 3 \text { and } 4 \text { hemorrhoids in our clinic between } 2009 \text { and } 2014 \text { were included in this study. The patient } \\
\text { data were reviewed by screening records. Gender, age, preoperative hemoglobin and hematocrit levels, operation } \\
\text { time, presence of thrombosis, number of packages, hospitalization time, early and late postoperative complications, } \\
\text { prolonged pain presence, and follow-up period were recorded. }\end{array}$ \\
\hline & $\begin{array}{l}\text { Results: In this period, surgical interventions were performed on } 365 \text { patients diagnosed with hemorrhoids. Among } \\
\text { these, } 159 \text { underwent LigaSure-assisted operations, while } 206 \text { were operated on by conventional methods. One hun- } \\
\text { dred forty-four (39.5\%) cases were female, while } 221(60.5 \%) \text { cases were male. The median age of the patients was } 40 \\
(19-82) \text { years in the LigaSure group and } 41(16-78) \text { years in the conventional method group. The operation time was } 15 \\
\text { (4-60) min in the LigaSure group and } 20(6-40) \text { min in the conventional method group. Postoperative analgesics were } \\
\text { given to the } 182(88.3 \%) \text { cases in the conventional group and } 107(67.3 \%) \text { cases in the LigaSure group. The time required } \\
\text { for returning to normal daily activity was } 6 \text { (1-15) days in the LigaSure group and } 7 \text { (1-30) days in the conventional } \\
\text { method group. }\end{array}$ \\
\hline & $\begin{array}{l}\text { Conclusion: In this study, LigaSure was determined to be superior to a conventional method in terms of operation time, } \\
\text { hospitalization period, postoperative analgesic requirements, time required for returning to normal daily activity, and } \\
\text { postoperative bleeding. }\end{array}$ \\
\hline & Keywords: Hemorrhoids, hemorrhoidectomy, LigaSure, milligan-morgan hemorrhoidectomy \\
\hline
\end{tabular}

\section{Cite this paper as:} Haksal MC, Çiftci A, Tiryaki Ç, Yazıııoğlu MB, Özyıldız M, Yıldiz SY. Comparison of the reliability and efficacy of Ligasure hemorrhoidectomy and a conventional MilliganMorgan hemorrhoidectomy in the surgical treatment of grade 3 and 4 hemorrhoids. Turk J Surg 2017; 33: 233-236.

'Department of Surgery, Medipol University School of Medicine, İstanbul, Turkey

2Department of Surgery, Kocaeli Derince Training and Research Hospital, Kocaeli, Turkey

Address for Correspondence Murat Burç Yazıcıoğlu e-mail: mbyazicioglu@gmail.com

Received: 23.02.2016 Accepted: 05.06.2016

\section{CCopyright 2017}

by Turkish Surgical Association

Available online at

www.turkjsurg.com

\section{INTRODUCTION}

Hemorrhoids are submucosal beds containing venules, arterial and smooth muscle fibers that are located on the anal canal. Hemorrhoidal disease is reported in approximately $5 \%$ of the general population, especially after 40 years of age $(1,2)$. Because hemorrhoids are normal anatomical components of the anal canal, treatment is indicated in only symptomatic cases. These symptoms include bleeding, thrombosis, and hemorrhoidal prolapses (3). Various methods are used in the treatment of hemorrhoids, including medical treatment, rubber band ligation, infrared photocoagulation, sclerotherapy, open hemorrhoidectomy, closed hemorrhoidectomy, whitehead hemorrhoidectomy, and stapler hemorrhoidectomy.

Conservative medical treatment is generally effective for grade 1 and 2 hemorrhoids; however, grade 3 and 4 hemorrhoids require surgical intervention. There are two especially well known surgical modalities for hemorrhoidectomy: open (Milligan-Morgan) (4) and closed (Ferguson) (5). These two methods have similar complications, such as blood loss and postoperative pain. Hospitalization time and time to return to work or normal daily activities are similar (6). LigaSure-assisted hemorrhoidectomy is an alternative to open hemorrhoidectomy in the treatment of grade 3 and 4 hemorrhoids (7). The LigaSure vessel sealing system (Covidien AS, Baltimore, US), is a hemostatic device that seals vessels by an optimized combination of radiofrequency ablation and pressure (8). LigaSure provides complete closure of arteries and veins with diameters of up to $7 \mathrm{~mm}$. This method has some advantages, it is a fast procedure, easy to learn and providing excellent bleeding control, minimal tissue damage, low postoperative pain, and short time to return to normal daily activity (9-11).

In this study, we aimed to compare the clinical results of LigaSure-assisted hemorrhoidectomy and Milligan-Morgan hemorrhoidectomy in our clinic.

\section{MATERIAL AND METHODS}

All patients read and singed a procedural consent form before the operation. Patients who underwent 
Haksal et al.

LigaSure and conventional hemorrhoidectomy

LigaSure-assisted hemorrhoidectomy or conventional hemorrhoidectomy for grade 3 and 4 hemorrhoids in our clinic in between January 2009 and January 2014 were included in this study. The patient data were reviewed retrospectively by screening patient records and by telephone calls. Patients of both genders with grade 3 and 4 bleeding hemorrhoids were included in the study. The age range was $16-82$ years. Patients with liver cirrhosis, uncontrolled diabetes mellitus, accompanying perianal disease, inflammatory bowel disease, pregnancy, or bleeding diathesis were excluded from the study. Colonoscopy was performed on all patients older than 50 years of age to exclude colon cancer. Anticoagulant or aspirin treatments were terminated five days before the treatment.

Patients underwent surgery under general or spinal anesthesia in the jackknife or lithotomy position. In the LigaSure group, the vessel of the package was sealed with LigaSure and the flaw was left open. In the other group who underwent surgery with the Milligan-Morgan method, the package was excised with cauter; the pedicle of the package was sutured, and the flaw was left open.

Gender, age, preoperative and postoperative $7^{\text {th }}$ day hemoglobin and hematocrit levels, operation time, presence of thrombosis, number of packages, residual disease (untreated residual packages due to anal stenosis risk in patients with more than three packages), hospitalization time, early and late postoperative complications, presence of prolonged pain, follow-up period and time to return to normal daily activity or work were recorded. Postoperative analgesia (a nonsteroidal anti-inflammatory drug) was provided only for patients with pain. Patients were contacted by telephone and asked about the presence of pain 30 days after hemorrhoidectomy in their follow-ups.

\section{Statistical Analysis}

Data were analyzed using the Statistical Package for the Social Sciences 20.0 for Windows (IBM Corp.; Armonk, NY, USA). Results were given as percentages, mean and standard deviation, or median and range. Quantitative variables were compared with Student's t-test or the Mann-Whitney $U$ test, and qualitative variables were compared with chi-square (Pearson's or Fischer's exact) tests. A p value less than 0.05 was considered to be significant.

\section{RESULTS}

In this period, surgical interventions were performed in 365 patients diagnosed with hemorrhoids. Thirty-one (8.5\%) cases could not be reached by telephone. Among those 365 cases, 159 underwent LigaSure-assisted operations, while 206 underwent operations by a conventional method. One hundred forty-four (39.5\%) cases were female, while 221 (60.5\%) cases were male. The median age of all the cases was 41 (16-82) years. Preoperative hemoglobin and hematocrit levels were 13.5 (7.2-17.2) and 39.4 \pm 5.9 , respectively, in the conventional method group and 13.9 (5.2-18.0) and $40.1 \pm 6.0$ in the LigaSure group. All patients were asked to return for follow-up on the $7^{\text {th }}$ day after operation in our clinic. The hemoglobin and hemato-

Table 1. Demographic features of patients

\begin{tabular}{|c|c|c|c|}
\hline Feature & Milligan-Morgan hemorrhoidectomy & LigaSure-assisted hemorrhoidectomy & p \\
\hline Patient number & 206 & 159 & \\
\hline Median age (years) & 41 & 40 & 0.615 \\
\hline \multicolumn{4}{|l|}{ Gender (\%) } \\
\hline Male & 122 & 99 & 0.556 \\
\hline Female & 84 & 60 & \\
\hline Preoperative hemoglobin ( $\mathrm{g} / \mathrm{dL})$ & $13.5(7.2-17.2)$ & $13.9(5.2-18.0)$ & 0.242 \\
\hline Preoperative hematocrit (\%) & $39.4 \pm 5.9$ & $40.1 \pm 6.0$ & 0.279 \\
\hline Postoperative $7^{\text {th }}$ day hemoglobin ( $\mathrm{g} / \mathrm{dL}$ ) & $13.1 \pm 1.9(n=119)$ & $13.4 \pm 1.9(n=87)$ & 0.334 \\
\hline Postoperative $7^{\text {th }}$ day hematocrit (\%) & $39.2 \pm 5.2(n=119)$ & $39.7 \pm 5.1(n=87)$ & 0.57 \\
\hline
\end{tabular}

Table 2. Features of LigaSure and conventional method

\begin{tabular}{|lccc}
\hline Feature & Milligan-Morgan hemorrhoidectomy & LigaSure hemorrhoidectomy & $\mathbf{p}$ \\
\hline Operation time [mean (range) $\mathrm{min}]$ & $20(6-40)$ & $15(4-30)$ & $<0.05$ \\
\hline Number of packages & $2(1-4)$ & $2(1-4)$ & $107(67.3)$ \\
\hline Analgesic requirement $\mathrm{n}(\%)$ & $182(88.3)$ & $13(8.2)$ & $<0.05$ \\
\hline Thrombosed hemorrhoids & $10(4.9)$ & $1(1-2)$ & 0.195 \\
\hline Hospitalization time (days) & $1(1-16)$ & $4(2.7)$ & $<0.05$ \\
\hline Re-operation $n$ (\%) & $3(1.6)$ & $6(1-15)$ & 0.704 \\
\hline Return to normal daily activity [mean (range) days] & $7(1-30)$ & $10(6.8)$ & $<0.05$ \\
\hline Prolonged pain n (\%) & $27(14.7)$ & $25.9 \pm 15.6$ & $<0.05$
\end{tabular}


Table 3. Complications

\begin{tabular}{|lccc}
\hline Complication & Milligan-Morgan hemorrhoidectomy & LigaSure hemorrhoidectomy & $\mathbf{p}$ \\
\hline Bleeding & $24(12.9)$ & $7(4.7)$ & $<0.05$ \\
\hline Necrosis & $1(0.5)$ & 0 & 0.999 \\
\hline Edema & $1(0.5)$ & $1(0.7)$ & 0.999 \\
\hline Residual disease & $10(5.4)$ & $5(3.4)$ & 0.370 \\
\hline Anal stenosis & $1(0.5)$ & $4(2.7)$ & 0.175
\end{tabular}

Datas were presented as n (\%)

crit levels in the first follow-up on the $7^{\text {th }}$ day were $13.1 \pm 1.9$ and $39.2 \pm 5.2$, respectively, in the conventional method group and $13.4 \pm 1.9$ and 39.7 \pm 5.1 , respectively, in the LigaSure group (Table 1). There was no statistically significant difference between the groups regarding age, gender, preoperative hemogram level, or postoperative $7^{\text {th }}$ day hemogram level. The number of packages treated with surgery was similar in the two groups in our study. The operation time was 15 (4-60) min in the LigaSure group and 20 (6-40) $\mathrm{min}$ in the conventional method group. Operation time was statistically significantly shorter in the LigaSure group.

Analgesia is not routinely provided to all hemorrhoidectomy cases after surgery in our clinic; it is reserved for patients who complain of pain. Postoperative analgesics were required in $182(88.3 \%)$ cases in the conventional group and in 107 $(67.3 \%)$ cases in the LigaSure group; the difference was statistically significant $(\mathrm{p}<0.05)$. Thrombosis was present in $10(4.9 \%)$ patients in the conventional method group and in $13(8.2 \%)$ cases in the LigaSure group ( $p=0.195)$. Re-operation was required because of bleeding in two (1\%) patients in the conventional method group and in four (2.7\%) patients in the LigaSure group $(p<0.05)$. In one case in the conventional method group, re-operation was required due to necrosis. All patients were discharged in good health after the re-operations.

The median hospitalization time was 1 ( 1 to 2 ) day in the LigaSure group and 1 (1-16) day in the conventional method group $(p<0.05)$. The time to return to normal daily activity was 6 (1-15) days in the LigaSure group and 7 (1-30) days in the conventional method group $(\mathrm{p}<0.05)$. The follow-up period was $25.9 \pm 15.6$ months in the LigaSure group and $28.3 \pm 15.7$ months in the conventional method group $(p<0.05)$. In this study, patients were asked about the presence of pain in the first 30 days after hemorrhoidectomy. Ten (6.8\%) of the cases who underwent operations with LigaSure and $27(14.7 \%)$ of the cases who underwent operations with a conventional method stated that they had pain $(p<0.05)$ (Table 2). Bleeding was reported in 31 cases in the first seven days. Among these, 24 underwent operations with a conventional method and 7 underwent LigaSure-assisted operations; the difference was statistically significant $(p<0.05)$. Two of the 24 and 4 of the 7 patients underwent re-operations for bleeding. Bleeding stopped spontaneously in the other cases. Regarding early complications, necrosis that was re-operated and then discharged on the $16^{\text {th }}$ day of hospitalization and edema was present in one patient in the conventional method group. In the LigaSure group edema was reported in one case. However dema was spontaneously resorbed in both group. Residual disease was determined in 10 (4.9\%) cases in the conventional method group and in 5 (3.1\%) cases in the LigaSure group $(p=0.370)$. Gas incontinence was reported in eight cases in the conventional method group and in two cases in the LigaSure group ( $p=0.195$ ). Anal stenosis was reported in one case in the conventional method group and four cases in the LigaSure group $(p=0.175)$. These five cases were treated with an anal dilatator without any further complications (Table 3 ).

\section{DISCUSSION}

Conventional methods have been used as surgical treatment modalities for grade 3 and 4 hemorrhoids for more than half a century (7). LigaSure is a device used in hemorrhoidectomy that coagulates vessels with diameters of up to $7 \mathrm{~mm}$, with thermal damage to the adjacent tissue of up to $2 \mathrm{~mm}$. This advantage enables rapid dissection of hemorrhoids without blood. Comparative studies of LigaSure with conventional methods can be found in the literature $(7,12)$.

According to a study by Peker et al., (12) in the LigaSure group, operation and return to work times were shorter than in the conventional group, while hospitalization and complication rates were similar. In a meta-analysis by Mastakov et al. (11) on 11 studies with 1,046 patients, in patients who underwent LigaSure operations, almost all outcome parameters were better than those of the conventional group except complications. In many studies included in the meta-analysis by Mastakov et al. (11), postoperative analgesic requirements were reported to be statistically significantly lower in the LigaSure group. Similarly, in our study, postoperative analgesic requirements were significantly lower in the LigaSure group (107 versus 182 patients). This significant difference is believed to be due to the transfixion suture on the vessel pedicle used in conventional methods. In many studies, the operation time was determined to be significantly shorter in LigaSure-assisted hemorrhoidectomy (12.5 vs. 29) (7), [22.3 vs. 27.4] (13), [9.4 vs.18.2] (14). Similarly, in our study with LigaSure, an easily applicable and trainable method, the operation time was significantly shorter than in the conventional method (15 versus $20 \mathrm{~min}$ ). In a study by Khanna et al. (7), the hospitalization period after operation (1.4 versus 3.2 days) was significantly shorter in the LigaSure group; however, in a study by Gentile et al. (13), the hospitalization periods of $24 \pm 2 \mathrm{~h}$ were similar in the two groups. In our study, the median hospitalization period was one day in both groups.

Rapid healing of the injury site accelerates return to normal daily activity. Patients who underwent LigaSure operations returned to their normal daily activities in a significantly 
Haksal et al.

LigaSure and conventional hemorrhoidectomy

shorter time than patients in the conventional group (6 versus $7 ; \mathrm{p}<0.05$ ). Chung and Wu (15) did not report any difference in these parameters; however, similar to our results. Milito et al. (9) and Sayfan et al. (16) (7.4 versus 18.6 days) defined shorter time periods for returning to normal daily activities in their LigaSure groups. While the postoperative bleeding ratio was $4.7 \%$ with LigaSure in our study, this ratio was $3.5 \%$ in the study by Khan et al. (7). The postoperative bleeding ratio was $12.9 \%$ with the conventional method in our study, whereas this ratio was similar in the study by Khan et al. (10.0\%) (7). The incidence of residual hemorrhoid in the study by Khan et al. (7) was lower in the LigaSure group (3.5\% versus $5 \%$ ); similarly, in our study, this ratio was determined to be lower in the LigaSure group (3.4\% versus 5.4\%). However, in both the literature and in our study, these differences were not statistically significant. Development of anal stenosis due to thermal damage from LigaSure usage has been described in many recent studies. Filingeri et al. (17) reported anal stenosis in 4 of 203 LigaSure-treated patients, Wang (18) determined it in 1 of 42 cases, and Gentile et al. (13) reported it in 1 of 25 patients. In our study, the results for anal stenosis were similar to the literature $(2.7 \%)(9,11)$. We treated five cases of anal stenosis with an anal dilator. The key point to prevent development of anal stenosis is to preserve mucosal bridging and the anoderm.

\section{CONCLUSION}

This retrospective study demonstrates the advantages of LigaSure compared with a conventional method in the treatment of grade 3 and 4 hemorrhoids. In this study, LigaSure was determined to be superior to a conventional method in terms of operation time, hospitalization period, postoperative analgesic requirements, time to return to normal daily activity, and postoperative bleeding.

Ethics Committee Approval: Authors declared that the research was conducted according to the principles of the World Medical Association Declaration of Helsinki "Ethical Principles for Medical Research Involving Human Subjects" (amended in October 2013).

Informed Consent: Written informed consent was obtained from patients who participated in this study.

Peer-review: Externally peer-reviewed.

Author Contributions: Concept - M.C.H.; Design - M.C.H., M.B.Y., Ç.T., A.Ç.; Supervision - M.C.H.; Resource - Ç.T.; Materials - M.B.Y., A.Ç.; Data Collection and/or Processing - A.Ç., Ç.T.; Analysis and/or Interpretation - A.Ç.; Literature Search - M.Ö.; Writing Manuscript - M.B.Y.; Critical Reviews - S.Y.Y.

Conflict of Interest: No conflict of interest was declared by the authors.

Financial Disclosure: The authors declared that this study has received no financial support.

\section{REFERENCES}

1. Arslani N, Patrlj L, Rajkoviç Z, Papes D, Altarac S. A randomized clinical trial comparing Ligasure versus stapled hemorrhoidectomy. Surg Laparosc Endosc Percutan Tech 2012; 22: 58-61. [CrossRef]

2. Cohen Z. Symposium on outpatient anorectal procedures. Alternatives to surgical hemorrhoidectomy. Can J Surg 1985; 28: 230231

3. Bullard KM, Rothenberg DA. Colon, Rectum, and Anus. In: Brunicardi F.C (ed). Swhwartz's Principles of Surgery, 8th edn. McGraw Hill, New York; 2005, pp. 1055-1117.

4. Milligan ETC, Naunton Morgan C, Jones L, Officer R. Surgical anatomy of the anal canal, and the operative treatment of hemorrhoids. Lancet 1937; 230: 1119-1124. [CrossRef]

5. Ferguson JA, Heaton JR. Closed hemorrhoidectomy. Dis Colon Rectum 1959; 2: 176-179 [CrossRef]

6. Ho YH, Cheong WK, Tsang C, Ho J, Eu KW, Tang CL, et al. Stapled hemorrhoidectomy-cost and effectiveness. Randomized, controlled trial including incontinence scoring, anorectal manometry, and endoanal ultrasound assessments at up to three months. Dis Colon Rectum 2000; 43: 1666-1675. [CrossRef]

7. Khanna R, Khanna S, Bhadani S, Singh S, Khanna AK. Comparison of Ligasure Hemorrhoidectomy with Conventional Ferguson's Hemorrhoidectomy. Indian J Surg 2010; 72: 294-297. [CrossRef]

8. Kennedy JS, Stranahan PL, Taylor KD, Chandler JG. High-burst strength, feedback controlled bipolar vessel sealing. Surg Endosc 1998; 12: 876-878. [CrossRef]

9. Milito G, Cadeddu F, Muzi MG, Nigro C, Farinon AM. Haemorrhoidectomy with Ligasure vs conventional excisional techniques: meta-analysis of randomized controlled trials. Colorectal Dis 2010; 12: 85-93. [CrossRef]

10. Nienhuijs $\mathrm{S}$, de Hingh I. Conventional versus Ligasure hemorrhoidectomy for patients with symptomatic Hemorrhoids. Cochrane Database Syst Rev 2009; 21: CD006761. [CrossRef]

11. Mastakov MY, Buettner PG, Ho YH. Updated meta-analysis of randomized controlled trials comparing conventional excisional haemorrhoidectomy with Ligasure for haemorrhoids. Tech Coloproctol 2008; 12: 229-239. [CrossRef]

12. Peker $K$, İnal $A$, Güllü $H$, Gül $D$, Sahin $M$, Özcan $A D$, et al. Comparison of Vessel Sealing Systems with Conventional. Iranian Red Crescent Medical Journal 2013; 15: 488-496. [CrossRef]

13. Gentile M, De Rosa M, Carbone G, Vincenzo P, Mosella F, Forestieri P. Ligasure Haemorrhoidectomy versus Conventional Diathermy for IV-Degree Haemorrhoids: Is It the Treatment of Choise? A Randomized, Clinical Trial. ISRN Gastroenterology 2011; Article ID 467258.

14. Tan KY, Zin T, Sim HL, Poon PL, Cheng A, Mak K. Randomized clinical trial comparing LigaSure haemorrhoidectomy with open diathermyhaemorrhoidectomy. Tech Coloproctol 2008; 12: 93-97. [CrossRef]

15. Chung YC, Wu HJ. Clinical Experience of Sutureless Closed Hemorrhoidectomy with Ligasure. Dis Colon Rectum 2003; 46: 87-92. [CrossRef]

16. Sayfan J, Becker A, Koltun L. Sutureless closed hemorrhoidectomy: a new technique. Ann Surg. 2001; 234: 21-24. [CrossRef]

17. Filingeri V, Gravante G, Baldessari E, Craboledda P, Bellati F, Casciani CU. Prospective randomized trial of submucosal hemorrhoidectomy with radiofrequency bistoury vs. conventional Parks' operation. Techniques in Coloproctology 2004; 8: 31-36. [CrossRef]

18. Wang JY, Lu CY, Tsai HL, Chen FM, Huang CJ, Huang YS, et al. Randomized controlled trial of LigaSure with submucosal dissection versus Ferguson hemorrhoidectomy for prolapsed hemorrhoids. World J Surg 2006; 30: 462-466. [CrossRef] 